\title{
Analysis of Potential Distribution and Size of Photovoltaic Systems on Rural Rooftops
}

\section{A contribution to an optimized local energy storage system with a remote sensing and GIS-based approach in Swabia, Germany}

\author{
Ana Gonzalez Quintairos ${ }^{1}$, Jochen Bühler ${ }^{2}$, Birgit Kleinschmit ${ }^{1}$ and Matthias Resch ${ }^{2}$ \\ ${ }^{1}$ Technische Universität Berlin, Germany · ana.gonzalezquintairos@campus.tu-berlin.de \\ ${ }^{2}$ Reiner Lemoine Institut, Berlin/Germany
}

Short paper

\begin{abstract}
The present study as part of the joint research project "Smart-Power-Flow" (at Reiner Lemoine Institute for Renewable Energies) focuses on modelling PV systems' distribution in German rural communities. Although solar power energy systems in Germany have been increasing exponentially for the last 20 years (WRITH 2014), the majority of literature on PV potential has focused on rooftop PV systems in urban regions, and a small number of publications consider the typology of small rural communities. These areas, although less populated than cities, are where the highest PV potential in Germany is expected (DENA 2010), and, at the same time, where the availability of laser scanning data is highly incomplete, or not affordable for small administrations or projects. Several authors have used remotely-sensed imagery to quantify the PV potential on a regional scale, but only few authors (KJELLSSON 2000, BERGAMASCO \& ASINARI 2011, Jo \& OTANICAR 2011) have attempted to use high-resolution images to quantify the suitable rooftop surface on a building basis, and none of them have addressed the particularities of rural communities.

The aim of this study is to create a methodology, which predicts the size and location of future photovoltaic systems on rooftops, based on generally accessible data, and that is easily reproducible on a building scale for other rural villages. The methodology's input data comprises high-resolution aerial imagery, GIS building footprints from the Landregister map, and the Bavarian database of photovoltaic systems. In addition, the method is tested using two types of images: a) official orthophotos from the Bavarian Land-survey Office, and b) Google Earth ${ }^{\mathrm{TM}}$ orthophotos, to assess the accuracy of freely available data to the project. The results are compared in the discussion section.
\end{abstract}

\footnotetext{
1 Project funded by the Federal Ministry of Economics and Technology (BMWi) under grant agreement no. 0325522A.
} 


\section{Methodology}

To accurately quantify the available rooftop area for PV installation, high-resolution orthophotos from the Bavarian Land-survey Office and Google Earth ${ }^{\mathrm{TM}}$ images (both recorded RGB bands with $0.2 \mathrm{~m}$ and $0.4 \mathrm{~m}$ spatial resolution, respectively) were processed in order to identify suitable rooftop areas, roof obstructions, and shadows. A Photovoltaic Calculator was used to quantify the PV energy generation potential in the experimental study area. Finally, the prognosis step predicts the likely PV-expansion pathway based on each rooftop PV potential and the scenarios of the German Energy Agency. Figure 1 presents a flow diagram of the methodological approach used to model spatially distributed PV potential for rural communities. The experimental site location is the village of Freihalden (JettingenScheppach) in the region of Swabia, Bavaria. The village was chosen among the 17 designated as critical in terms of electricity grid by the regional network operator, who is also a partner in this study. Only 5\% of buildings are blocks, $17 \%$ are two-family homes, and the remaining $77 \%$ are single houses. Freihalden presents a perfect settlement pattern characteristic of rural communities in Germany and Central Europe.

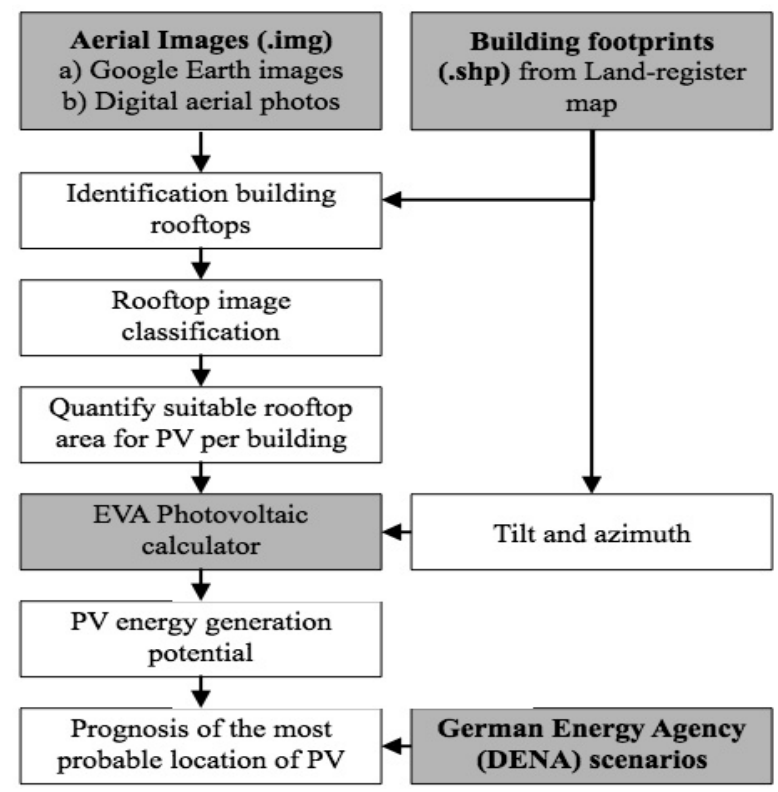

Fig. 1:

Methodology applied to estimate spatially distributed PV potential in rural communities

\subsection{Isolating Building Rooftops}

First, the current status quo was analysed, cross-referencing the files from the Bavarian register of PV systems and the Land-register map. The Bavarian Register of PV systems offers free access throughout its webpage. These buildings were excluded from the dataset in order to avoid assigning them as potential buildings in the future. Cropping the images from the Land-register map with building footprints isolated the building rooftops. Directly integrating the building footprint shapefile limits the subsequent pixel-based image analysis within the rooftop surface, and thus excludes data from outside the building rooftop. 


\subsection{Suitable Area Computation}

To identify the suitable areas per rooftop, a supervised image classification is conducted on the subset image of the building rooftops. Particularly, the purpose is to identify four zones: (1) shadows, (2) obstructions, (3) suitable areas, and (4) non-suitable areas. The extension of Semi-automatic Image Classification from QGIS was used to perform this step, seeking to build a methodology based on accessible data and open-source software. The output of the image classification analysis, shown in Figure 2, is converted to vector data and the potential suitable area is assigned to each building. Rooftop orientation and average slope are spatially joined to each rooftop.

\subsection{PV Energy Calculation and Prognosis Expansion Pathway}

PV Calculator software was used to quantify the PV energy generation potential in the study area. EVA is a tool created at the Reiner Lemoine Institute that is able to calculate energy production of PV systems and its financial analysis. Finally, the prognosis step predicts the likely PV-expansion pathway based on each rooftop PV potential, and the scenarios of the German Energy Agency. In its Dena-Netzstudie II (2010), the German Energy Agency generated two scenarios for the expansion of PV and wind energy sources at municipal level in Germany, with a horizon year of 2030. The scenarios are made to fulfil German national goals concerning the implementation of renewable energy sources in the electricity market. Each municipality is assigned to a category with an expansion factor ranging from 0,7 to 5 - depending on the population density and the already existing solar plants in relation to the German average. The prioritization of the buildings, until fulfilling the DENA goal for Freihalden, follows the criteria of the highest specific yield, namely the expected annual energy $(\mathrm{kWh})$ by the installed capacity of the building $(\mathrm{kW})$. The output of the method is stored in a database including the central coordinates of each building.

\section{Results and Discussion}

Freihalden was found to have 43 buildings with PV systems already installed on their rooftops, which represented an already installed nominal power of $571 \mathrm{kWp}$. The classification of the Bavarian land-register orthophoto concluded that $82 \%$ of the buildings in the community have adequate areas with more than $10 \mathrm{~m}^{2}$ suitable for PV, whereas in the classification of the Google Earth ${ }^{\mathrm{TM}}$ orthophoto, $78 \%$ of the buildings are considered to have adequate areas for PV. It was found that $39,6-40,1 \%$ of total rooftop area is considered suitable for PV. This number can be used a rule-of-thumb for future studies in the area. The total PV technical potential of Freihalden reaches $3170 \mathrm{kWp}$. Individual building potential ranges from 1 potential $\mathrm{kWp}$ to $42 \mathrm{kWp}$, and the specific yield varies from 980,1 to 763,1 $\mathrm{kWp} / \mathrm{kWh}$. From the 412 buildings composing the village, 98 of those with highest potential expected to install PV systems in the next 17 years in order to achieve the Bavarian renewable energy goals for 2030. We conclude that for the same training areas, both images present almost the same suitable area $-39,5 \%$ and $40,1 \%$-, which supports the classification procedure. It was found that the classification decreases in accuracy depending on the material of the roofs. In this manner, red roofs have the highest accuracy. On the contrary, black and very dark roofs exhibit similar spectral signatures between suitable, non-suitable and shadow areas, ergo the classification delivered worse results. Overall the Bavarian 
land-register orthophoto presented a higher accuracy in all roof types (red roofs: $91 \%$; grey roofs: $87 \%$; black roofs: $76 \%$ ) compared to the Google Earth ${ }^{\mathrm{TM}}$ image (red roofs: $88 \%$; grey roofs: $82 \%$; black roofs: $71 \%$ ). As a consequence, the Bavarian land-register orthophoto has a weighted average accuracy of $89 \%$ while the Google Earth ${ }^{\mathrm{TM}}$ image has a weighted average accuracy of $84 \%$. This can be explained due to the fact that Google Earth $^{\mathrm{TM}}$ images have lower ground resolution and pixel depth. The average suitable area for PV in the village $(40,1 \%)$ is consistent with the studies conducted for Germany by LöDL et al. (2010), Kerber (2011) and the InTERnational ENERgy AgEncy (2002), - 44,8\%, $40 \%$, and $40 \%$, respectively, - with the advantage that the PV potential per building is also calculated. If applied to another village, the quantity of suitable area will be adapted to the amount of obstructions existing in that village and to its roof configuration, making the methodology much more precise. On the other hand, supervised classification can hardly be automated. Even if signatures for each class are stored and saved as separate files, it is likely that they cannot be applied to images that were taken under other weather conditions. This implies longer working times and specific remote sensing knowledge if the methodology is to be correctly applied. The prognosis expansion pathways were found to identify with the highest implementation potential from all buildings classified as suitable, only small to medium size buildings, all facing south, in both images. South-facing buildings yield higher energy production than buildings facing south-east or south-west with a similar suitable area, and hence are ranked higher according to the criteria of the highest specific yield. There is a $430 \mathrm{kWp}$ difference between the PV technical potential based on the Google Earth ${ }^{\mathrm{TM}}$ image classification in comparison to the Bavarian land-register orthophoto classification, which represents a $16 \%$ lower technical potential. The lower technical potential is a consequence of the fewer number of buildings identified in the Google Earth ${ }^{\mathrm{TM}}$ image classification in comparison to the Bavarian land-register orthophoto classification.

\section{Conclusion and Outlook}

We have proved that it is possible to use open-source software and freely available images to download from Google Earth ${ }^{\mathrm{TM}}$ and still be able to obtain significantly accurate results. Google Earth ${ }^{\mathrm{TM}}$ images are already processed images and have lower spatial and radiometric resolution. Nevertheless, accuracy assessments provide reasonably good results. If future research following the approach of this study is to be conducted, steps can be implemented in order to improve the classification output. Segmentation of rooftops can also deliver meaningful improvements. Automating the sequential steps, by writing R or python code, would speed up the methodology. To improve the prognosis expansion pathway, the acquisition of extra data, including social variables, becomes an important requirement. Without additional data that can enlighten the situation when a person decides on installing a PV system, the expansion pathways may be observed only as an orientation.

\section{References}

Bergamasco, L. \& AsinARI, P. (2011), Scalable methodology for the photovoltaic solar energy potential assessment based on available roof surface area: Further improvements by ortho-image analysis to Turin (Italy). Solar Energy, 85 (11), 2741-2756. 
Deutsche ENERgIE-Agentur GMBH (2010), Dena-Netzstudie II . Integration erneuerbarer Energien in die deutsche Stromversorgung im Zeitraum 2015-2020 mit Ausblick 2025.

International ENERGy AgENCy (IEA) (2002), Potential for Building Integrated Photovoltaics. IEA-PVPS T7-4, Paris, 2002.

JO, J. H. \& OTANICAR, T. P. (2011), A hierarchical methodology for the mesoscale assessment of building integrated roof solar energy systems. Renew. Energy, 36 (11), 29923000 .

KERBER, G. (2011), Aufnahmefähigkeit von Niederspannungsverteilnetzen für die Einspeisung aus Photovoltaikkleinanlagen. Technische Universität München.

KJELlSSON, E. (2000), Potential for building integrated photovoltaics - A study for Sweden. IEA-PVPS Task, 2-4 p.

LöDl, M., Kerber, G., Witzmann, R., Hoffmann, C. \& Metzger, M. (2010), Abschätzung des Photovoltaik-Potentials auf Dachflächen in Deutschland. Proc. 11th Symposium Energieinnovation, Graz, Austria, 10-12 February 2010, 14 p.

WIRTH, H. (2014), Recent facts about photovoltaics in Germany. Frauhofer Institute for Solar Energy Systems ISE, Berlin, 5 p. 